\title{
Evolutionary Medicine: A Powerful Tool for Improving Human Health
}

\author{
Ernie Hood • Kristin P. Jenkins
}

Published online: 13 February 2008

(C) Springer Science + Business Media, LLC 2008

\begin{abstract}
Modern evolutionary research has much to contribute to medical research and health care practices. Conversely, evolutionary biologists are tapping into the rapidly expanding databases of medical genomic information to further their research. These two fields, which have historically functioned in almost complete isolation, are finding mutual benefit in the exchange of information. The long-term benefits of this synthesis of two major areas of research include improved health care. Recently, efforts to catalyze this relationship have brought together evolutionary biologists, medical practitioners, anthropologists, and ethicists to lay the groundwork for further collaboration and exploration. The range of overlap is surprisingly broad and potentially invaluable.
\end{abstract}

Keywords Evolution · Medicine - Genomics .

Human health $\cdot$ Lifestyle $\cdot$ Infectious disease

\section{Evolution and Medicine}

Evolution has not traditionally been considered to be an important aspect of medicine, and medical practitioners and researchers have not traditionally approached their work from the perspective offered by evolutionary biology. Medical practice tends to focus on the immediate, or

\section{E. Hood}

3929 A Red Hawk Rd,

Hillsborough, NC 27278, USA

e-mail: bkthrough@earthlink.net

K. P. Jenkins $(\bowtie)$

2024 W. Main St. Suite A200,

Durham, NC 27705, USA

e-mail: kjenkins@nescent.org proximate, causes of disease, including genetics and lifestyle, to identify a potential treatment. An evolutionary viewpoint pushes the focus out farther to look at long-term ecological relationships, including symbiotic bacteria, parasites and pathogens, historical lifestyles, and the genetics of populations. Conversely, evolutionary biologists have not traditionally paid much attention to the medical implications or applications of their findings, with a few exceptions such as the study of emerging infectious diseases. Other evolutionary studies have seemed far removed from contemporary human health issues.

Recently, however, these traditions have been giving way to a new approach, as researchers and medical practitioners discover connections based on evolutionary biology that are leading them to new conclusions about their respective fields. Evolution is providing clues about puzzling medical results, and studies of human health are giving us new information about the rate and driving forces of evolution. Initiatives such as the Human Genome Project and the Haplotype Map have provided new tools for studying evolution and human health. Genes are important, environment is important, the interaction between the two is important- but so is human evolution, as it exerts an ongoing influence on characteristics of the human population.

In May 2007, evolutionary and medical researchers, doctors, ethicists, and anthropologists met at the National Evolutionary Synthesis Center to catalyze the emerging scientific discipline known as evolutionary medicine. Although the participants work on different aspects of human health, they all realize the value of evolution in their work. As the title of the meeting-Evolution in Contemporary Human Populations: Medical, Genetic and Behavioral Implications (Govindaraju 2007) - suggests, this group of scientists clearly share the belief that evolution is going on in contemporary human populations. In fact, a recent study 
presents evidence that evolution may have been occurring even faster in human populations than expected over the past 10,000 years (Hawks et al. 2007).

The field of medicine has developed to address the wide array of environmental and lifestyle-induced diseases. Over time, doctors have learned more about the relationship between environment and disease, including factors such as hygiene and lifestyle. More recently, genomic studies have opened the door to studying genetic differences between populations, bringing us the possibility of more effective individualized medicine. All in all, medicine seems to be making great progress in preventing, treating, and curing disease without including evolutionary information. So what does understanding our evolutionary history add to our ability to improve human health?

\section{Shaped by History}

It has been shown that human evolution, in the form of natural selection for particular traits, can occur over the short term-just a few generations, "the blink of an eye to evolutionary biologists," according to Yale University evolutionary biologist Stephen Stearns, one of the NESCent meeting organizers. Continued lactose tolerance in adults is an example of a trait that has evolved in certain populations within the last 10,000 years, since the domestication of milkproducing livestock (Tishkoff et al. 2006; Swallow 2003). "If a doctor can become aware of how all these different traits actually interact with each other, then you begin to see your individual patient as something that isn't just the symptom sitting in front of you in the office that day," Stearns says. "If you treat that symptom, then the perspective of evolutionary biology will tell you what all of the possible associated reactions are. The point is, they're a bit broader, and they may contain more surprises than a strictly medical orientation would give you. Evolution gives you a broader view of the whole way an organism reacts, and why it does sobecause it's been shaped by evolution in certain ways." Psychiatrist Randolph Nesse of the University of Michigan, a strong advocate of evolutionary medicine, agrees: "Once a doctor starts understanding how the body came to be, instead of seeing the body as a machine - which it's not- he or she starts seeing the body as a product of natural selection, where everything in the body is pretty good, because it's got to be, and nothing is perfect.... This perspective is needed for literally every aspect of the body that's vulnerable to disease. Why hasn't natural selection made it better? There are always good reasons."

Among those reasons is the idea that evolution involves an array of trade-offs, compromises in selection that favor one trait at the inevitable expense of another. Stearns, Nesse, and David Haig of Harvard University eloquently explain the importance of evolutionary trade-offs in the initial chapter of Evolution in Health and Disease (Stearns and Koella 2007):

No trait is perfect. Every trait could be better, but making it better would make something else worse. Our vision could be as acute as that of an eagle, but the price would be a decreased capacity to detect color, depth, and movement in a wide field of vision. If the bones in our wrists were thicker they would not break so readily, but we would not be able to rotate our wrists in the wonderful motion that makes throwing efficient. It the stomach made less acid we would be less prone to ulcers, but more prone to GI infections. Every trait requires analysis of the trade-offs that limit its perfection.

Consideration of these compromises that have evolved over time can guide medical decisions about altering our physiology and behaviors.

The evolutionary trade-off between survival and reproductive success of the individual is an interesting example. Reproduction is expensive, on many fronts. Just looking at mating success, high testosterone levels may provide a man with a competitive advantage in securing a mate, but will also decrease his resistance to pathogens and parasites (Muehlenbein and Bribiescas 2005). A woman who has regular and frequent menstrual cycles has more opportunities to become pregnant, but is also at increased risk of cancer (Strassmann 1999). Exposure to higher hormone levels, either incidentally or by design, can have unexpected side effects because of this evolutionary trade-off. Reproductive success is ultimately the more important factor in evolution, as one's evolutionary fitness is measured by the number of offspring that survive to reproductive age themselves. The compromise results from the fact that we produce only one or two offspring at a time, and human offspring require extended parental care. Humans who threw everything into mating but did not survive long enough to raise the few resulting offspring would be unsuccessful because their offspring would not survive either. Radically changing traits that have been shaped over time runs the very real risk of tipping the balance in unexpected, and potentially unpleasant, directions.

\section{New Environment}

Homo sapiens has been around for about 100,000 years, and both fossils and genomic studies present evidence of ongoing evolution in $H$. sapiens. As a species, $H$. sapiens has experienced many lifestyle changes-some generated by culture, others by new or changing environments. Anthropology can provide valuable insights into our past, and this information can improve our application of 
evolutionary medicine (Trevathan 2007). We learn from studies of ancient societies, but also from the few remaining traditional hunter-gatherer societies and by comparisons between different societies.

A major shift in lifestyle was the development of agriculture. Agriculture led to many changes, including dietary alterations and exposure to zoonoses from domesticated animals. Agriculture required groups to abandon a mobile hunter-gatherer lifestyle and live in sedentary populations, such as farming villages. Ultimately, agriculture provided the ability to support large urban populations. Sedentary groups encounter issues such as accumulation of wastes and transmission of epidemic diseases (Armelagos et al. 2005), issues that increase with population size. Even more recently, increases in expected life span and change in diets have led to a rise in the frequency of chronic diseases (Armelagos et al. 2005; Leonard 2007). These changes in the environment and the increase in population size have the potential to create a surge in the rate of evolutionary change (Hawks et al. 2007).

Clinicians and biomedical researchers need to incorporate an understanding of this mismatch to modernity into their explorations of pathophysiology. In simple terms, many aspects of our modern environment and lifestyle, including diet, exercise, exposure to chemicals, hygienic practices and circumstances, and a variety of other elements, are mismatched to our bodies' evolutionary state. For example, if - thanks to our prehistoric ancestors - our physiology is evolutionarily hardwired for low caloric intake and intense physical activity, our rich modern diets and sedentary lifestyles mismatch our innate metabolism (Neel 1962; Wang and Mariman 2008). Evolutionary medicine tells us that many of today's so-called "diseases of civilization" that are so highly prevalent and growing rapidly in incidence, such as diabetes, obesity, and cardiovascular disease, may well be fueled by a metabolic mismatch (Leonard 2007). This phenomenon can be readily observed in contemporary populations that have undergone a "nutrition transition" in which rapid socioeconomic, demographic, and technological changes have brought profound changes in diet and activity patterns, often resulting in sudden and widespread increases in metabolic disorders. For example, a recent paper examined the changes in diet and health in the rapidly urbanizing black South African population. The study found that the change in lifestyle was accompanied not only by an improvement in micronutrients but also by an increase in obesity and chronic diseases (Vorster et al. 2005). Characterizing such mismatches through the use of today's analytical tools promises to shed important new light on the etiology of these and many other common, complex disorders (e.g., autoimmune, inflammatory, and mental/behavioral conditions) and offers an innovative approach to the identification of novel interventions and therapies.
Continuing to look at mismatches between what we are prepared for evolutionarily and what we experience with a modern lifestyle, we find puzzling results that require an understanding of our evolutionary history to solve. For example, recent studies have demonstrated a connection between decreased intestinal parasite load and increased incidence of autoimmune diseases such as asthma (Lau and Matricardi 2006). In one study, children who had been dewormed showed an increase in the occurrence of allergic reactions to house mites. Why? What was the link between removing worms and developing allergies? One proposed explanation is the "hygiene hypothesis" (Strachan 1989), which takes an evolutionary view and considers that the historically "normal" condition for humans is a constant barrage of parasites and that the immune response evolved in response to these conditions. An over-reactive immune system is a recognized cause of allergies, and it turns out that the presence of helminthes, common intestinal parasites, actually increases regulation and control of the immune response. When these children were dewormed, regulation of their immune response decreased, allowing an allergic response to house mites. An interesting application of this research is the experimental use of intestinal parasites in the treatment of autoimmune diseases such as irritable bowl syndrome, Crohn's disease, and multiple sclerosis (Wickelgren 2004).

Evolution can also shed light on normal physiological responses such as vomiting and fever and guide medical interventions (Nesse and Williams 1998). In terms of evolution, a trait will be selected for if it provides some advantage. An example is "morning sickness"- the nausea and vomiting suffered by $75 \%$ of pregnant women (Badell et al. 2006). Nausea and vomiting are commonly experienced in the first and second trimesters, and generally, foods such as meat, fish, poultry, and eggs elicit the strongest responses. Clearly, feeling nauseated and vomiting frequently are unpleasant experiences at the very least, and hospitalization for rehydration is frequently required. Occasionally, more serious complications arise. However, there is significant evidence that this physiological process is associated with successful pregnancies (Weigel and Weigel 1989). One tested hypothesis posits that this response is beneficial to both mother and embryo because it reduces the mother's intake of, and embryo's exposure to, potentially toxic chemicals and pathogens during key developmental stages (Flaxman and Sherman 2000). In addition, the foods most commonly avoided are animal products which tend to harbor more pathogens than plant foods. The immune system of pregnant women is depressed to avoid rejection of the fetus, so both mother and embryo are at higher risk from pathogens. The benefits of this response may well justify the discomfort and risks - or at least provide some psychological comfort to suffering women. 


\section{Evolution of Infectious Disease}

Evolution is not something that happened long ago and then stopped. It remains an active force in the modern world not only in human populations but also in the pathogens and parasites with which we live. One need look no farther than the local news or health clinic for proof. The evolution of antibiotic-resistant strains of tuberculosis made the news in spring 2007 when a man with extremely drugresistant (XDR) TB made multiple international flights (CNN 2007). Fortunately, no one else was infected in this instance, but the recent evolution of drug-resistant TB has revived old fears, especially in places where the complicated medical treatment required for these strains is not available. Evolutionary medicine can help physicians take into account the effects of people's changing environments and lifestyles. Human behaviors such as conflict, poverty, and urbanization provide opportunities for infectious diseases to spread (Halstead 1996). Today, more people live in areas of high population density - a change from the more traditional small community. High population density urban centers are ideal for transmission of pathogens, particularly when coupled with high rates of poverty (Armelagos et al. 2005).

Old antagonists are not the only concern. Behaviors that bring humans into contact with pathogen reservoirs in wildlife, such as logging and the exotic animal and bush meat trades, also create opportunities for the transmission of "zoonoses" - pathogens normally found in animal hosts but capable of infecting humans (Patz et al. 2004). For example, logging brings roads to new areas, providing easy access for local inhabitants who come to hunt for food. In the process, hunters either become prey themselves as they are infected by novel pathogens or bring the pathogens back to populated areas in the form of bush meat (Chomel et al. 2007). Sometimes, the infection is relatively benignfor example, children often pick up worms from household pets - but sometimes, the transfer is deadly. The ancestor of the human immunodeficiency virus (HIV) is the simian immunodeficiency virus, which is found in a wide range of primate species and rarely causes disease in the primate host (Hahn et al. 2000) despite the fact that HIV is devastating in humans.

Taking an evolutionary approach to medicine can help us deal with novel pathogens by increasing our understanding of the pathogen and facilitating the development of appropriate responses. When the mysterious severe acute respiratory syndrome (SARS) virus emerged on the world scene, researchers quickly gathered information about its physical structure, life cycle, and genetics. By comparing its characteristics with those of known viruses, researchers were able to quickly identify the novel SARS virus as a coronavirus (WHO 2003). That crucial piece of information allowed health care professionals to develop appropriate diagnostic tools, preventive measures, and treatments based on knowledge of how other coronaviruses behave. Additionally, the information about viral type allowed field researchers to identify the source of the infection based on known hosts of coronaviruses. Civet cats, sold live in meat markets, were frequently found to be infected with a SARS virus. Further research indicated that horseshoe bats, which were also sold in these markets, had a more ancestral variant of the virus (Britigan 2005; Lau et al. 2005; Wendong et al. 2005). The virus was also found to be more widespread in bats. The civet cats probably act as an intermediate host, or "amplifier." Understanding the lifestyle and environment in which the disease arose helped to rapidly control it, preventing a feared worldwide epidemic.

\section{Genomics, Evolution, and Medicine}

Recently, new technologies such as improved genome sequencing and microarrays are generating huge quantities of genomic information. Bioinformatic tools for analysis of this ever-expanding volume of raw data are developing apace, and genomics, the study of whole genomes, has become an independent biological discipline. The medically relevant value of this data is the potential to identify the genes underlying disease for the purpose of developing treatment or even prevention. Evolutionary medicine plays a critical role in the interpretation and application of this information, since human evolutionary history has shaped the genome. Humans as a species are relatively young with a mere 100,000-year history. The pattern of our relatively recent global dispersal from our home in Africa is reflected in our genes. Different populations demonstrate our common ancestry and recent isolation during dispersal (Kidd and Kidd 2007). Interpretation of genomic data must take our evolutionary history into account to yield useful applications.

One of the most informative analytical approaches is comparison between sequences, either of small genomic regions or entire genomes. By examining differences and similarities between the genomes of two organisms, researchers learn about ancient genes that have deep evolutionary roots and about genetic differences between organisms that make them unique. In comparing the human genome with those of closely related primates, we learn what minor differences may be important keys to our human condition. Comparisons between the human genome and more distantly related organisms provide information about ancient genes that play important roles in fundamental processes such as development and physiology. This can be done on various levels. Microarrays allow comparisons between sets of genes or two entire genomes. Bioinformatic tools allow comparisons of multiple genes, sections of genomes, or entire genomes. 
A new method that exploits both microarray technology and genome sequencing is the genome-wide association (GWA) study. In a GWA, a microarray of all of the known human single nucleotide polymorphisms (which are simply a change in one nucleotide) is screened for differences between diseased and healthy individuals. To give the study statistical significance, samples from thousands of individuals are used. In a recent GWA, researchers identified genomic polymorphisms potentially associated with seven different diseases (Wellcome 2007). This information can be used to guide future research on the genetics of these diseases. The GWA is yet another method based on enormous data sets that may lead to significant advances in medicine. Resources to promote this kind of megaanalysis include the Human Genome Project and the HapMap, which uses collections of single-nucleotide differences as markers for larger genetic regions. The HapMap is important because genomes of any two humans differ only by $0.1 \%$. Researchers can use the general markers from the HapMap to narrow down their searches to areas of variation.

An important key to drawing useful information from genomic data is the ability to link a genotype to a phenotype. This is a difficult problem for several reasons: genomic data are not usually collected from a specific individual with an extensive health history; family medical histories are rarely complete; environmental conditions vary between populations, etc. One approach to deal with this issue is the use of large, long-term studies of specific populations. The Framingham Heart Study (FHS) is the quintessential large cohort, long-term study. Initiated in 1948 to investigate the causes of heart disease and stroke, the project collected data on more than 5,000 people living in Framingham, Massachusetts. In addition to birth, marriage, reproduction, and death data, the participants were given physical exams and lifestyle interviews. Followup physicals were given every 2 years. Adult children of the original cohort and the children's spouses, as well as the original cohort's grandchildren, also participated in the study. This study allowed researchers to identify the major environmental risk factors for cardiovascular disease, such as smoking and high blood pressure. Because of the extensive data collected for the project and the virtually unprecedented length of the study, the FHS is incredibly valuable to medical researchers. The data are now being mined by groups researching other diseases such as obesity and eye and lung diseases. Other studies of large or multigenerational cohorts are also under way using different populations.

Diddahally Govindaraju is the director of the FHS Genetics Laboratory at the Boston University School of Medicine and was one of the organizers of the NESCent meeting. He is enthusiastic about the concept of applying evolutionary principles to cohort data such as that generated over nearly six decades in the FHS. "I was essentially sitting on a wealth of medical data that has been collected for the last 50 years," he says. "Having been raised on evolutionary biological thought in the first part of my professional life, I looked at this and realized that the doctors were not looking at these data from an evolutionary biology perspective." Dr. Govindaraju and his colleagues have organized a working group to explore the FHS from an evolutionary viewpoint. The group proposes to look for microevolutionary changes in the study population and to use the extensive medical data to correlate differences in genomic inheritance and phenotypic outcomes.

Given the vast quantities of data available because of the genomics revolution and multi-generational, longitudinal clinical cohorts such as the Framingham Heart Study, it has become increasingly clear that the analysis of new and existing data from an evolutionary perspective promises to yield important insights into long-standing questions about human physiology and pathophysiology. Combined with the development of new technologies that have given us entire genomes and the tools with which to study them, these vast data sets have the potential to launch an evolutionary medicine revolution.

\section{Ethical Considerations}

It should come as no surprise that evolutionary medicine comes with a unique set of ethical issues. A field that encompasses so many aspects of who we are as individuals and has the power to provide better health to so many people also has the potential to be abused in a variety of ways. Positive applications such as personalized medicine, in which an individual would receive the most beneficial medical treatment based on his or her genomic makeup, hold great promise for improving the efficacy of medical care. However, it is no great stretch to imagine that genetic information about individuals could be misused outside of the medical realm. Communication of complex evolutionary medicine concepts to the general public will be fraught with cultural perspectives, biases, and historical antagonism, and miscommunication could have serious consequences for individuals and society.

Privacy concerns are a major issue. When so much data, including genetic information, are being gathered on so many people, how can a participating individual's privacy be protected while simultaneously making the information as widely available as possible (NHGRI 2007)? Also, the use of particular populations in studies is a double-edged sword. In some cases, researchers can learn a great deal by studying a particular group whose members share a lifestyle or ancestry. But how can that group be certain that the information will not be used against them, by insurance 
companies, for example? On the other hand, if beneficial information is gleaned from one group, how is that benefit made available to other groups who were not studied?

Another important issue to consider is the concept of race (Kittles and Weiss 2003). Particularly in the USA, the sensitive nature of this issue cannot be overstated. The genetic concept of race and the social concept of race are not the same. In colloquial use, the term race designates a group of people based on their appearance and culture. Among the research community the definition of race has not been consistent or well defined. Scientifically, race correlates roughly with shared genetic ancestry usually based on geographic proximity, but even these parameters fail to clearly delineate groups. There is some debate as to whether race is a legitimate biological concept at all. Social concepts of race also influence how research is done by biasing selection of populations to be sampled, methodologies, and other aspects of research. Paradoxically, some diseases are associated with socially defined races, such as Tay-Sachs disease in the Ashkenazi Jews, making it necessary to take into account these social groupings in conducting research.

\section{Conclusion}

The exciting potential of evolutionary medicine to yield important new insights into long-standing questions about human physiology and pathophysiology was summed up by Stearns: "When you see how evolution illuminates those questions, you see there's the potential for a new way of looking at them to save literally hundreds of millions of lives. That is an enormous payoff, and it's the kind of thing that people in medical research have felt all of their lives, but it's a new motivation for evolutionary biologists, and it's a revelation to them to realize that they could bring that to the table."

Acknowledgments The authors would like to thank the organizers and participants of the Evolution in Contemporary Human Populations: Medical, Genetic and Behavioral Implications meeting at NESCent for providing access to the meeting and supporting information, and reviewers for their helpful comments.

\section{References}

Armelagos GJ, Brown PJ, Turner B. Evolutionary, historical, and political economic perspectives on health and disease. Soc Sci Med. 2005;61:755-65.

Badell ML, Ramin SM, Smith JA. Treatment options for nausea and vomiting during pregnancy. Pharmacotherapy 2006;26(9):1273-87.

Britigan BE. Bats: the missing SARS reservoir. Journal Watch Infectious Diseases. Nov. 18. http://infectious-diseases.jwatch. org/cgi/content/full/2005/1118/1. Accessed Jan. 3, 2008; 2005.

Chomel BB, Belotto A, Meslin F-X. Wildlife, exotic pets, and emerging zoonoses. Emerg Infect Dis. 2007;13(1):6-11.
CNN.com, Man knew he had TB before flying to Europe. http://www. cnn.com/2007/HEALTH/conditions/05/30/tb.flight/index.html. Accessed Jan. 3, 2008; 2007.

Flaxman SM, Sherman PW. Morning sickness: a mechanism for protecting mother and embryo. Q Rev Biol. 2000;75(2):113-48.

Govindaraju D, Stearns S, Beyers P. Evolution in contemporary human populations: Medical, Genetic and Behavioral Implications Meeting at NESCent. http://www.nescent.org/science/awards summary.php?id=0011. Accessed Jan. 3, 2008; 2007.

Hahn BH, Shaw GM, DeCock KM, Sharp PM. AIDS as a zoonosis: scientific and public health implications. Science 2000;278:607-14.

Halstead SB. Human factors in emerging infectious diseases. East Mediterr Health J. 1996;2(1):21-9.

Hawks J, Wang ET, Cochran GM, Harpending HC, Moyzis RK. Recent acceleration of human adaptive evolution. PNAS 2007;104(2):20753-8.

Kidd KK, Kidd JR. Human genetic variation of medical significance. In: Stearns SC, Koella JC, editors. Evolution in health and disease. 2nd ed. Oxford: Oxford University Press; 2007.

Kittles RA, Weiss KM. Race, ancestry, and genes: implications for defining disease risk. Annu Rev Genomics Hum Genet. 2003;4:33-67.

Lau K, Matricardi PM. Worms, asthma, and the hygiene hypothesis. Lancet 2006;367(9522):1556-8.

Lau SKP, Woo PCY, Li KSM, Huang Y, Tsoi HW, Wong BHL, Wong SSY, Leung SY, Chan KH, Yuen KY. Severe acute respiratory syndrome coronavirus-like virus in Chinese horseshoe bats. PNAS 2005;102(39):14040-5.

Leonard WR. Lifestyle, diet and disease: comparative perspectives on the determinants of chronic health risks. In: Stearns SC, Koella JC, editors. Evolution in health and disease.. 2nd ed. Oxford: Oxford University Press; 2007.

Muehlenbein MP, Bribiescas RG. Testosterone-mediated immune functions and male life histories. Am J Human Biol. 2005; 17:527-58.

National Human Genome Research Institute, Genetic Discrimination. http://www.genome.gov/10002077. Accessed Jan. 3, 2008; 2007.

Neel JV. Diabete mellitus: a "thrifty" genotype rendered detrimental by "progress". Am J Hum Genet. 1962;14:353-62.

Nesse RM, Williams GC. Evolution and the origins of disease. Iowa: Scientific American; 1998, p. 86-93. (November).

Patz JA, Daszak P, Tabor GM, Aguirre AA, Pearl M, Epstein J, Wolfe ND, Kilpatrick AM, Foufopoulos J, Molyneux D, Bradley DJ, Members of the Working Group on Land Use Change Disease Emergence. Unhealthy landscapes: policy recommendations on land use change and infectious disease emergence. Environ Health Perspect. 2004;112(10):1092-8.

Stearns SC, Koella JC. (eds) Evolution in health and disease. 2nd ed. Oxford University Press; 2007.

Strachan DP. Hay fever, hygiene, and household size. Br Med J. 1989;299:1259-60.

Strassmann BI. Menstrual cycling and breast cancer: an evolutionary perspective. J Women's Health. 1999;8(2):193-202.

Swallow DM. Genetics of lactase persistence and lactose intolerance. Annu Rev Genet. 2003;37:197-219.

Tishkoff SA, Reed FA, Ranciaro A, Voight BJ, Babbitt C, Silverman JS, Powell K, Mortensen HM, Hirbo JB, Osman M, Ibrahim M, Omar SA, Lema G, Nyambo TB, Ghori J, Bumpstead S, Pritchard JK, Wray GA, Deloukas P. Convergent adaptation of human lactase persistence in Africa and Europe. Nat Genet. 2006;39(1):31-40.

Trevathan WR. Evolutionary medicine. Annu Rev Anthropol. 2007;36:139-54.

Vorster HH, Venter CS, Wissing MP, Margetts BM. The nutrition and health transition in the North West Province of South Africa: a review of the THUSA (Transition and Health during Urbanization of South Africans) Study. Public Health Nutr. 2005;8(5):480-90. 
Wang P, Mariman EDM. Insulin resistance in an energy-centered perspective. Physiology and Behavior 2008 (in press) DOI 10.1016/j.physbeh.2007.11.008.

Weigel RM, Weigel MM. Nausea and vomiting of early pregnancy and pregnancy outcome. A meta-analytical review. Br J Obstet Gynaecol. 1989;96(11):1312-18.

Wellcome Trust Case Control Consortium. Genome-wide association study of 14,000 cases of seven common disease and 3,000 shared controls. Nature 2007;447:661-78.
Wendong L, Shi Z, Yu M, Ren W, Smith C, Epstein JH, Wang H, Crameri $\mathrm{G}, \mathrm{Hu} \mathrm{Z}$, Zhang H, Zhang J, McEachern J, Field H, Daszak P, Eaton BT, Zhang S, Wang L. Bats are natural reservoirs of SARS-like coronaviruses. Science 2005;310: 676-9.

Wickelgren I. Can worms tame the immune system. Science 2004;305:170-71.

World Health Organization (WHO), Coronavirus never before seen in humans is the cause of SARS. http://www.who.int/mediacentre/ news/releases/2003/pr31/en/. Accessed Jan. 3, 2008; 2003. 